\title{
A Participatory Live Music Performance with the Open Symphony System
}

\author{
Kate Hayes \\ Guildhall School of Music \& \\ Drama \\ London, EC2Y 8DT, UK \\ ellen.hayes@stu.gsmd.ac.uk

\section{Mathieu Barthet} \\ Queen Mary University of London \\ Centre for Digital Music \\ London, E1 4NS, UK \\ m.barthet@qmul.ac.uk \\ Leshao Zhang \\ Queen Mary University of London \\ Centre for Digital Music \\ London, E1 4NS, UK \\ l.zhang@se14.qmul.ac.uk \\ Nick Bryan-Kinns \\ Queen Mary University of London \\ Centre for Digital Music \\ London, E1 4NS, UK \\ n.bryan-kinns@qmul.ac.uk

\section{Yongmeng Wu} \\ Queen Mary University of London \\ Centre for Digital Music \\ London, E1 4NS, UK \\ yongmeng.wu@qmul.ac.uk \\ Permission to make digital or hard copies of part or all of this work for \\ personal or classroom use is granted without fee provided that copies are \\ not made or distributed for profit or commercial advantage and that \\ not made or distributed for profit or commercial advantage and that
copies bear this notice and the full citation on the first page. Copyrights \\ copies bear this notice and the full citation on the first page. Copyrights
for third-party components of this work must be honored. For all other \\ for third-party components of this
uses, contact the Owner/Author. \\ uses, contact the Owner/Author.
Copyright is held by the owner/author(s) \\ CHI'16 Extended Abstracts, May 07-12, 2016, San Jose, CA, USA \\ ACM 978-1-4503-4082-3/16/05. \\ http://dx.doi.org/10.1145/2851581.2889471
}

\begin{abstract}
Our Open Symphony system reimagines the music experience for a digital age, fostering alliances between performer and audience and our digital selves. Open Symphony enables live participatory music performance where the audience actively engages in the music creation process. This is made possible by using stateof-the-art web technologies and data visualisation techniques. Through collaborations with local performers we will conduct a series of interactive music performance revolutionizing the performance experience both for performers and audiences. The system throws open music-creating possibilities to every participant and is a genuine novel way to demonstrate the field of Human Computer Interaction through computer-supported cooperative creation and multimodal music and visual perception.
\end{abstract}

\section{Author Keywords}

Interactive Performance; Creativity; Audience Participation; Directed Improvisation; Visualisation; Live

\section{ACM Classification Keywords}

H.5.2. Information interfaces and presentation (e.g., $\mathrm{HCI}$ ) User Interfaces, J.5 Arts and humanities. 


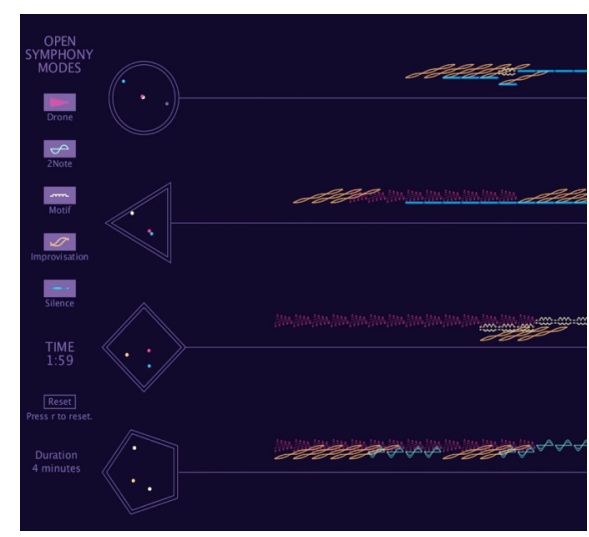

Figure 1: Open Symphony score example.

\section{Introduction}

Open Symphony is a new collaborative music-making system which aims to embrace digital technology as a facilitator of collaborative experiences between audience members and performers in a live setting. The idea was conceived to acknowledge and capitalise on a listeners ever-growing digital presence within live music settings; designing a system to resolve the disconnect between reality and digital-reality and transform digital technology's possibilities to encourage more present and meaningful experiences. This paper proposes an interactive and participatory music performance engaging both audience and performers using Open Symphony. Such system challenges the status quo of the music performance format and notions of sender and receiver. By reconfiguring the chain of communication and redistributing the skills of musicianship, it overrides the unidirectional relationship between audience and performer, establishing a coleading partnership for music-making. The shared roles of participants create a unique environment which draws upon the improvisational and performance expertise of the musician and the active listening and reflection position of the audience. Although applications are not restricted to specific musical genres, the system is suitable for the "directed improvisation" musical form in which performers receive a set of external directions that contribute to establish what and how they will play. This is facilitated by the web-based application we developed which can run on any mobile devices with access to Internet. Photos and a video demonstrating the system in a live interactive setting can be found at: http://bit.ly/os_photos and http://bit.ly/os_visvideo.

The project widens the scope for audience participation to include non specialists. The digital platforms are user friendly and are demonstrated prior to performance. As participation does not require prior musical skills and that the system proved to be easy to use with a quick learning curve, any interested CHI 2016 attendees will get a chance to actively take part in the performance creative process. Previous audience participants have commented that their engagement in the music was increased ("I was paying close attention to my musician and how they were reacting to different input", "My presence was not passive, but instead, very active"). The reach of Open Symphony's possibilities extend to re-interrupting the range of traditional music settings, from orchestral performances to rock/pop stadium concerts, establishing new music composition structures and performance styles, creating enhanced, immersive experiences, broadening the understanding and appreciation of music creation and reaffirming the central role that music can provide for social cohesion.

\section{Related Works}

In a musical context, composers and music-makers have regularly allowed space for a performers' interruption, with varying levels of control, while performers can encourage an active response from the audience within the performance. Audiences have been used to create compositional material as in Matthew Herbert's piece An Apple A Day from his 2005 album, Plat Du Jour which engaged his live audiences in his creative process by recording 3500 people biting an apple at the same time, while artists and music ensembles seek new ways to engage audience such as Improv Everywhere's project Conduct Us where members of the public became a conductor for an orchestra. However, these systems do little in inviting the audience into the creative process of music making or extending the musical collaboration to the non- 


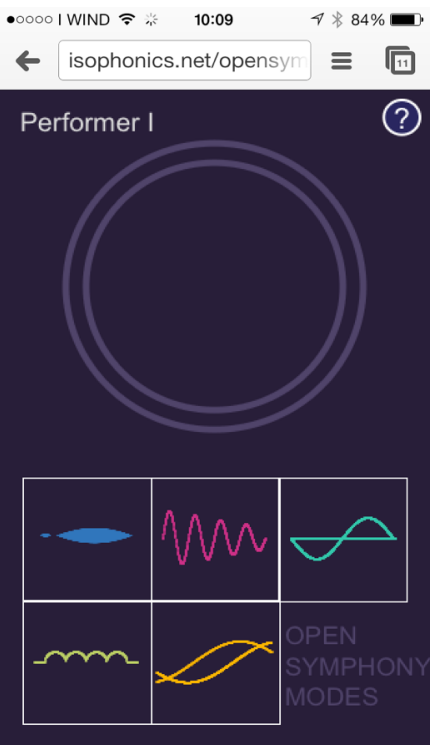

Figure 1: Open Symphony web app user interface. musician. Open Symphony takes the position that an actively engaged audience can experience everything that is inherent in the space music creates to become part of the performance itself. A key practitioner of this ideal is Bobby McFerrin who not only leads audiences to become an integral part of the performance but has highlighted the dormant music potential within nonmusic specialists. Several systems facilitating collaborative music creation relying on audienceaudience interaction have been developed. For example Polymetros [2] enables several co-located users to create and control a repetitive musical phrase collaboratively. In terms of performer-audience interaction, wristbands such as Xylobands [3] start to be used at major pop concerts; performers can control the light on individual audience member's device and use them together as an additional source of visual output for the performance. However, although a range of approaches to supporting audience-performer interaction were summarized by Kim-Boyle [3] (e.g. network-based instruments, generative score mechanisms), they rarely look at live creative interaction between audience and performers, which is the primary focus of Open Symphony. One key example of creative audience-performer interaction is Mood Conductor [4], a system which opens a direct communication channel from audience to performers in the context of live improvised music performance, by allowing audience to choose desired emotions on their mobile device in order to conduct performers and influence the way they will play.

\section{Open Symphony Architecture}

Musically, the system relies on structural music components which offer simplicity of understanding for non-musicians along with creative potential for performers. There are five music modes available i) drone, ii) 2-note motif, iii) motif, iv) free improvisation v) silence. These provide building blocks to create harmony, rhythm, melody, texture and some free choice for the performer. The experience challenges the role of audience and performer, redefining the direction of musical creativity and expertise resulting in spontaneous and collaborative new music compositions. The traditional musical score and central conductor are replaced by deconstructed music modes and multiple audience conductors. The musical outcome arises through the selected options of the audience and the creative prowess of the performers. As a listener, these parameters provide previously unavailable access to creating music, while musicians are offered new platforms to explore and devise music. The system has been enjoyed by musicians proficient in improvisational music and those interested in new music performances. It can provide various degrees on control from a linear score (heterophony - simultaneous variation of a single melodic line) to an open brief (eg. free improvisation). Within all variants, the musicians are afforded flexibility for individual interruption while also responding musically to their fellow performers and audience conductors. Performer participants commented positively on the creative potential it provides, "Gave me options to create in a different way to how I normally do", "freedom to experiment with notes and styles" and the sense of control and ownership, "puts the musician and composer (audience) on equal ground", "it gave people more opportunity to take ownership of the piece", "I reckon they would engage more with what one could argue is their own work".

The Open Symphony digital system consists of three components: i) a visual client for presenting visual 


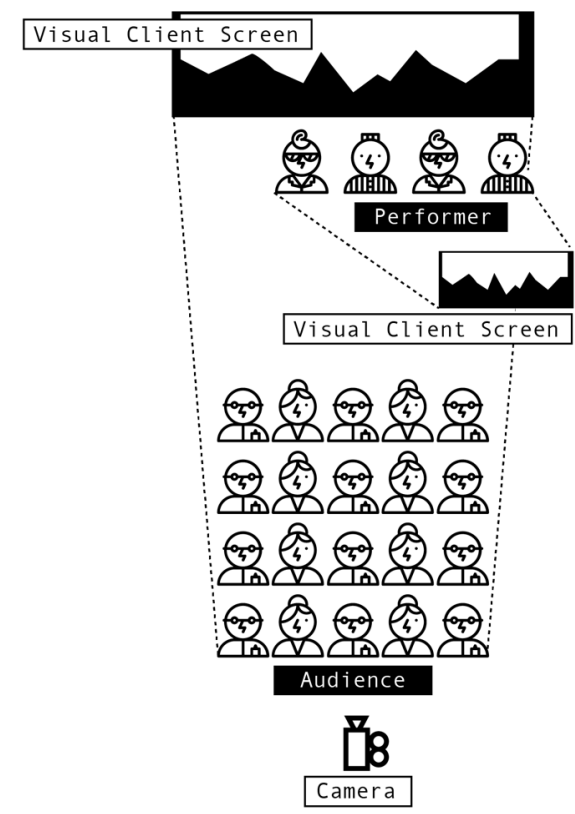

Figure 3: Open Symphony performance setting example. feedback to audience and performers (see Figure 1); ii) a smartphone-friendly web-based application for audience voting (see Figure 2); iii) a server component supporting the interaction between the visual client and the web application. It enables the overall system with i) a voting system for audience interaction supported by the web app, (ii) an automated audience-to-performer grouping assignment achieved during connection to the app, (iii) quasi real-time visualisation of a symbolic score for performers generated based on the audience's votes, and (iv) a web-based client/server

communication model to exchange user- and performance-related data.

\section{Performance Procedure}

Consenting audience members will be invited to connect to the web application on their mobile devices using the URL http://bit.ly/opensymphony or a QR

Code. They will then automatically be assigned to a performer by the app and be able to select playing modes amongst those available. To make it easier for audiences, the performance is designed to gradually increase the number of active modes they can select. We aim to see Open Symphony as a platform to create planned and/or spontaneous collaborations between musicians from broad experience and provenance. The CHI 2016 Open Symphony live performance will engage an ensemble of local performers. The performers will first be introduced to the system before the conference and then on-site interactions to prepare the performance. An example of setting for the Open Symphony performance is given in Figure 3 . Visual feedback for the audience and performers are provided by screens located at the back and on the side of the stage, respectively.
Conclusion The interaction pathways enabled by Open Symphony transform the traditional unidirectional chain of musical communication by providing a feedback process from audience to performers. Thus, a new form of interactive live music performance is accessible to either small or large audiences. Open Symphony fuses a community's resources and expertise to create a new folk music of the digital age. For musicians, it presents new territory for composition and performance while for audiences, through acknowledging the potential musicianship within any participants, it creates a new output for these qualities and may serve as a vector for learning new musical skills.

\section{Acknowledgments}

This work has been partly supported by EPSRC grant EP/L019981/1, the China Scholarship Council, and Arts Council England (Sound and Music Audience Labs).

\section{References}

[1] B. Bengler and N. Bryan-Kinns. 2013. Designing collaborative musical experiences for broad audiences. In Proc. of the 9th ACM Conf. on Creativity \& Cognition. ACM, 234-242.

[2] Xylobands. 2015. Xylobands. http://www.xylobands.com/xylobands/xylobands/

[3] D. Kim-Boyle. 2009. Network musics: Play, engagement and the democratization of performance. Contemporary Music Review 28, 4-5, 363-375.

[4] G. Fazekas, M. Barthet, and M. B Sandler. 2014 Novel Methods in Facilitating Audience and Performer Interaction Using the Mood Conductor Framework. Sound, Music, and Motion. Lecture Notes in Computer Science, 8905, Springer, 122147. 